\title{
Aggressive Thyroid Carcinoma Showing Thymic-Like Differentiation (Castle): Case Report and Review of the Literature
}

\author{
CARLo CAPPELli, ANDREA TIRONI*, GIAN PIETRO MARCHETTI**, ILENIA PIROLA, ElVIRA De MARTINO, \\ ANDREA DELBARBA, MAURIZIO CASTELLANO AND ENRICO AGABITI ROSEI
}

\author{
Department of Medical and Surgical Sciences, Internal Medicine and Endocrinology Unit, University of Brescia \\ *II Pathological anatomy, University of Brescia \\ **Pulmonology Unit, Spedali Civili, Brescia
}

\begin{abstract}
Carcinoma showing thymic-like differentiation (CASTLE) is a rare tumour of the thyroid, which arises from ectopic thymic tissue or remnants of branchial pouches. A systematic review of English literature evidences less than thirty cases; from them, it clearly appears that CASTLE is considered an indolent slow-growing neoplasia even when lymph nodes metastasis are present. We describe a case of very aggressive CASTLE, which showed seeding along fine needle aspiration tract.
\end{abstract}

Key words: Thyroid cancer, Carcinoma showing thymic-like differentiation, Castle

(Endocrine Journal 55: 685-690, 2008)

CARCINOMA showing thymic-like differentiation (CASTLE) is a rare tumour of the thyroid arising from ectopic thymic tissue or remnants of branchial pouches. This cancer was described by Miyauchi et al. [1] as intrathyroidal epithelial thymoma in 1981, but only ten years later, Chan and Rosaj denominated it as carcinoma showing thymic-like elements describing its clinical and pathological features [2]. In 2004, this disease has been designated as an independent clinicopathologic entity of thyroid tumors in the WHO classification [3]. A systematic review of English literature evidences less than thirty cases; from them, it clearly appears that CASTLE is considered an indolent slowgrowing neoplasia even when lymph nodes metastasis are present $[4,5]$. This data is confirmed in a recent study by the Japanese Society of Thyroid Surgery [5].

Received: December 6, 2007

Accepted: January 10, 2008

Corresponding to: Dr. C. CAPPELLI, Department of Medical and Surgical Sciences, Internal Medicine and Endocrinology Unit, University of Brescia., c/o 2 Medicina Spedali Civili di Brescia, Piazzale Spedali Civili n 125100 Brescia, Italy
We describe a case of very aggressive CASTLE, which showed seeding along fine needle aspiration tract.

\section{Case Report}

A 73-year-old male was seen in the Pulmonary Division in October 2005 for gradually worsening hoarseness and dyspnea. His personal past medical history was not significant. Physical examination revealed the absence of vesicular respiration in the left chest and the presence of palpable cervical right lymph nodes. A chest X-ray showed a large left pleural effusion involving three-fourths of the hemithorax. The laboratory findings were normal except for a slight increase of CA 19.9 and CA 15.3 [52 U/L (n.v. <40) and $32 \mathrm{U} / \mathrm{L}$ (n.v. $<30$ ), respectively].

Thoracentesis was performed, draining $4500 \mathrm{cc}$ of yellow fluid. Two days later, a thoracoscopy showed multiple small white nodules on the parietal, diaphragmatic, and visceral pleura of the lower left lobe, which were submitted to biopsy (Fig. 1); finally, a talc 


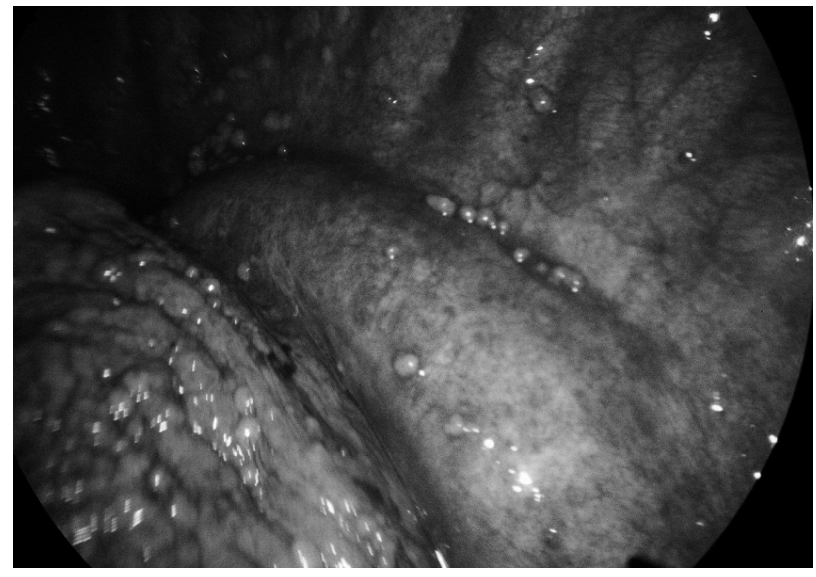

Fig. 1. Thoracoscopy: small white nodules on parietal and visceral pleura.

poudrage was performed.

The cytological examination of the pleural fluid showed numerous malignant cells that were not otherwise typified. The pleural biopsy showed large, spindle-shaped cells with lightly eosinophilic cytoplasm, focal intercellular bridges, squamous pearl-like disposition and small distinct nucleoli. Occasional mitoses and focal necrosis were present. Lymphocytes were interspersed among neoplastic aggregates (Fig. 2a). The proliferation marker MIB1 was expressed by $30 \%$ of the tumour cells.

Immunohistochemistry was strongly positive for pancytokeratin, epithelial-membrane-antigen and CD5; positive for calretinin; focally positive for CEA and CD117; and negative for TTF1, thyroglobulin, calcitonin, chromogranin, synaptophysin, WT1, cytokeratin 5/6 and B72.3.
A computed total body tomography (CT) staging showed a diffuse left pleural thickening with nodular lesions (maximum diameter of $2 \mathrm{~cm}$ ), paraesophageal and epiaortic lymph nodes, and an irregular thyroid mass in the right lobe (maximum diameter of $3 \mathrm{~cm}$ ) with slight contrast enhancement and pathological ipsilateral cervical lymph nodes. A neck ultrasound confirmed the presence of a very hypoechoic thyroid lesion with an irregular margin and abnormal lateral cervical lymph nodes.

Fine needle aspiration cytology of both the thyroid and lateral cervical lymph was promptly performed. The cytological and immunohistochemical features were superimposable to those observed in the pleural biopsy (Fig. 2b, c). Our diagnosis was carcinoma showing thymus-like differentiation of the thyroid with right lateral cervical lymph nodes and pleural metastasis (see Table 1).

Two months later, the patient had a weight loss of $14 \mathrm{~kg}$, accompanying pain or dyspnea. The physical examination revealed cutaneous lesions in the sites where thoracoscopy and fine needle aspiration cytology were performed (Fig. 3). A new CT showed worsening of the pleural disease with diffuse bilateral thickening and an increase in the number and size of the nodules (maximum diameter of $3.3 \mathrm{~cm}$ ). Paraesophageal, epiaortic, and lymph nodes and cervical lymph nodes were also increased. Cutaneous lesions were consistent with cancer seeding. A scintigraphy with ${ }^{111}$ In-octreotide was performed two days after the CT scan, but it was negative.

We started a cycle of chemotherapy with adryamicin $\left(45 \mathrm{mg} / \mathrm{m}^{2}\right)$, cisplatin $\left(50 \mathrm{mg} / \mathrm{m}^{2}\right)$ and cyclophosphamide $\left(600 \mathrm{mg} / \mathrm{m}^{2}\right)$, but the patient died from acute res-
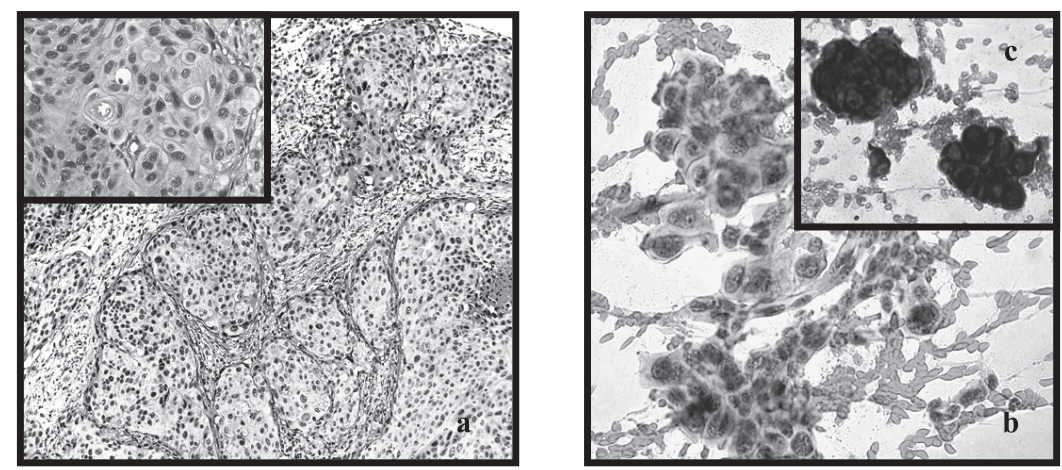

Fig. 2. Pleural biopsy: confluenht nests of epithelioid malignant cells with squamoid features (a) (H-E, original magnification $\times 100$. Inset $\mathrm{H}-\mathrm{E}$, original magnification $\times 250$ ). Fine needle aspiration of thyroid/right lateral cervical lymph node showing epithelioid malignant cells (b), anti-CD5 strongly positive (c). PAP, original magnification $\times 250$. 
Table 1. Staining patterns of several malignant tumours in the thyroid gland to be differentiated from CASTLE and pleural mesothelioma.

\begin{tabular}{|c|c|c|c|c|c|c|c|c|c|c|c|c|}
\hline & Calcitonin & CEA & Pancytokeratin & $\begin{array}{c}\text { Cytokeratin } \\
5 / 6\end{array}$ & Calretinin & WT1 & $\mathrm{Tg}$ & Chromogranin & TTF-1 & EMA & CD5 & CD117 \\
\hline $\begin{array}{l}\text { Anaplastic } \\
\text { carcinoma }\end{array}$ & - & - & + & $+1-$ & - & & - & - & - & + & - & $-1+$ \\
\hline $\begin{array}{l}\text { Squamous cell } \\
\text { carcinoma }\end{array}$ & - & - & + & + & - & & - & - & - & + & - & $-1+$ \\
\hline $\begin{array}{c}\text { Metastasis } \\
\text { tumour }\end{array}$ & - & $-/+$ & + & $+/-$ & & & & $+/-$ & - & + & - & \\
\hline $\begin{array}{l}\text { Insular } \\
\quad \text { carcinoma }\end{array}$ & - & - & + & - & - & & + & - & + & + & - & \\
\hline $\begin{array}{l}\text { Papillary } \\
\text { carcinoma }\end{array}$ & - & - & + & - & - & & + & - & + & + & - & $-1+$ \\
\hline $\begin{array}{l}\text { Medullary } \\
\text { carcinoma }\end{array}$ & + & $-/+$ & + & - & - & & - & + & & + & - & $-1+$ \\
\hline Mesothelioma & - & - & + & + & + & + & - & - & - & + & - & $-1+$ \\
\hline CASTLE & - & $-/+$ & + & - & $-/+$ & & - & - & - & + & + & + \\
\hline Present Case & - & + & + & - & + & - & - & - & - & + & + & + \\
\hline
\end{tabular}
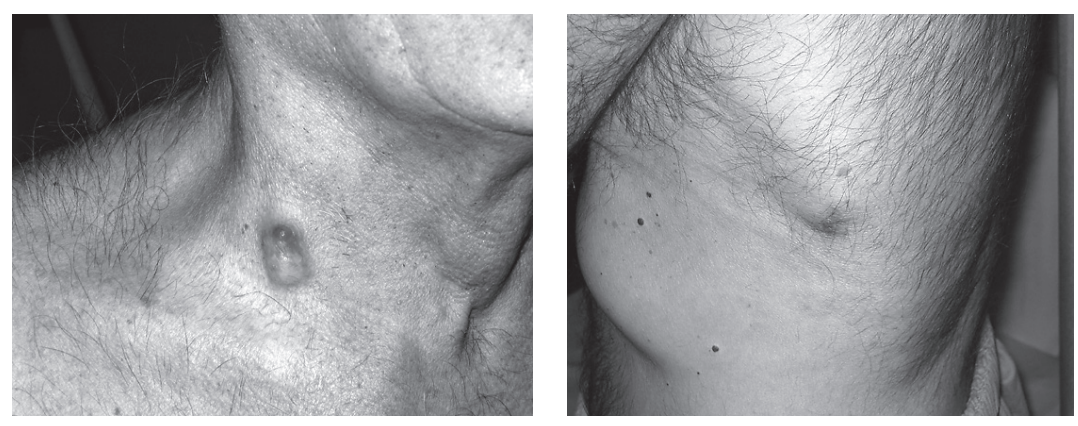

Fig. 3. Right neck and left hemithorax cutaneous lesions; with the permission of the patient.

piratory insufficiency the day after the first treatment. Autopsy was not performed.

For the rarity and moreover for the very aggressiveness of the present case, we submitted all the cytological samples to the Pathological groups of the Mayo Clinic. They confirmed our diagnosis after a meticulous examination of the slides.

\section{Discussion}

Tumours with thymic differentiation can occur in or near the thyroid gland. Chan and Rosai defined four clinic-pathologic entities: ectopic hamartomatous thymoma, ectopic cervical thymoma, spindle epithelial tumour with thymus-like differentiation (SETTLE), and Carcinoma showing thymic-like differentiation (CASTLE) [2]. This tumour is postulated to arise from either ectopic thymic tissue or remnants of bran- chial pouches, which retain the potential to differentiate along the thymic line $[4,5]$.

CASTLE is a very rare tumour that typically occurs in adults in the fifth decade of life with a slight female predominance $(\mathrm{M} / \mathrm{F}=1: 1.3)[4,5]$. Less than thirty cases of Carcinoma showing thymic-like differentiation have been reported in the literature, four of which include distant metastases (brain, liver and pulmonary) $[2,5,6-8]$; nevertheless, it is considered an indolent neoplasm with a good prognosis $[4,5,9-11]$.

The diagnosis of CASTLE is difficult not only because of its rarity, but also because its histological appearance is similar to those of lymphoepithelioma, thymic carcinoma and squamous cancer [2]. In addition, more common thyroid tumours are present in the differential diagnosis (e.g. papillary, follicular and medullary carcinoma). Typically, papillary or follicular differentiation is not seen [11], but pathologically, squamous cell carcinoma, papillary or medullary thy- 
roid carcinoma with squamous differentiation and anaplastic thyroid cancer must be taken into consideration $[2,4,12]$. Even if cytology shows characteristic cells (e.g., squamoid cells with eosinophilic cytoplasm, oval nuclei with small distinct nucleoli), morphology alone may not be sufficient for a diagnosis. The expression of immunohistochemical markers is in fact helpful for the correct interpretation of the samples $[5,10,11,13-$ 15]. Recently, Ito et al., in reviewing 23 cases of CASTLE, showed a strong sensitivity $(82 \%)$ with a specificity of one hundred percent for CD5, even if the diagnosis was already based on samples [5]. Also in our experience, as reported above, the diagnosis was suspected based on H\&E-stained slides, while the immunohistochemistry was helpful in strengthening the diagnosis. Indeed, the unusual presentation of the present case in terms of aggressiveness challenged physicians to differentiate the diagnosis from lung squamous cell carcinoma, mediastinal thymic carcinoma and overall, from pleural mesothelioma. This was also due to the fact that the tumour cells expressed a mesothelial marker (calretinin). Indeed, CC Pan et al. recently demonstrated that one third of thymic carcinomas and/or cancers derived from thymic cells are positive for calretinin [16], while, on the other hand, all other mesothelial markers of the present case were negative (e.g., WT1, Cytokeratin 5/6) either on the pleural, thyroid or lymph node cytology. Conversely, CEA and CD5 were strongly positive. Table 1 reports the characteristic staining patterns of several malignant tumours of the thyroid, mesothelioma and CASTLE, and those obtained in the present case [15, 16-18].

Immunohistochemistry was again helpful to differentiate the diagnosis from lung squamous cell carcinoma, nevertheless by the help of the computed tomography images. In fact, the CT negative for lung lesions associated to an immunohistochemistry strongly positive for CD5 and negative both for cytocheratin $5 / 6$ and calretinin, permitted us to exclude a lung squamous cell cancer.

Recently, Tomiyama et al. reported, in a large series of patients that CT is the best procedure for the diagnosis of mediastinal thymic carcinoma [19]. In agreement with this data, we could exclude this tumour on the basis of CT images.

Other distinctive features of our patient were the presence of distant metastases at the time of diagnosis and the very rapid progression of cancer. To our knowledge, none of the reports have described a case of CASTLE with distant metastasis at the time of diagnosis. Indeed, in four patients, metastasis developed during the follow-up period (mean time: $33.5 \pm 14.1$ months (range 14-48) [2, 7, 8], also involving the pleura [5].

The high aggressiveness of the case described is also evidenced by cancer seeding along fine needle aspiration tract (Fig. 3). This peculiar cancer dissemination has been suggested for other neoplasms [14, 20 22], especially for pleural mesothelioma [23], but never in CASTLE disease. Taking our experience into account, prophylactic radiotherapy treatment of the area(s) submitted to fine needle aspiration could be considered and recommended in CASTLE, as was successfully adopted in mesothelioma [24].

Our report describes the oldest patient ( 73 years old) affected by CASTLE. Mizukami et al. reported a 71 year old subject who died of local recurrence 6 months after surgery [25]. Considering the limits derived from the small number of patients, we could still speculate that patient age could have a prognostic significance.

Due to the rarity of this particular type of malignancy, and also to the indolent aggressive behaviour assigned to CASTLE, data on adjuvant or palliative chemotherapy are anecdotal. Kakudo et al. treated a patient with lung metastasis with adryamicin, endoxan and ACNU without clinical response [8]. Roka et al. proposed a chemotherapy regime adopted for thymic carcinoma in two patients (cisplatin, epirubicin and irinotecan), with, unfortunately, the same result [4]. More recently, Kusada et al. treated a patient with paclitaxel, but he died after the second cycle of chemotherapy [26]. These clinical data suggest that effective drugs for this disease have not been found. Moreover, the treatments that are currently in place have well known high levels of toxicity.

Also, there are only limited radiotherapy data available, with discordant results $[2,4]$, even if very recently Ito et al. reported a good response to radiotherapy in term of recurrences [5], and to our knowledge, no other treatment has been proposed. The presence of somatostatin receptors, described in few malignant thymomas [27], induced us to perform a scintigraphy with ${ }^{111}$ In-octreotide, but in contrast to the experience of Lin et al. [18], the scintigraphy was negative.

Taking the few therapeutic experiences into account, the "good" behaviour of this neoplasm and the good response of our patient to talc poudrage, we 
decided to perform a follow-up. After two months, following an unexpected dramatic worsening of the patient's conditions, polychemotherapy was initiated, but the patient died from respiratory insufficiency the following day.

\section{Conclusion}

We report the first case of CASTLE with lateral cervical lymph node metastasis, pleural involvement and a dramatically aggressive progression. In spite of the more common indolent course of this disease, this case indicates the possibility of a rapidly fatal evolution of CASTLE. Cancer seeding along the tract of the biopsy is described for the first time in this report.

\section{Acknowledgements}

We are very grateful to Kevin O. Leslie, M.D, Tom Colby M.D., and Henry Tazelaar (Laboratory Medicine and Pathology, Mayo Clinic) for their consultation.

\section{References}

1. Miyauchi A, Kuma K, Matsuzuka F, Matsubayashi S, Kobayashi A, Tamai H, Katayama S (1985) Intrathyroidal epithelial thymoma: an entity distinct from squamous cell carcinoma of the thyroid. World J Surg 9: $128-135$.

2. Chan JK, Rosai J (1991) Tumors of the neck showing thymic or related branchial pouch differentiation: a unifying concept. Hum Pathol 22: 349-367.

3. Cheuk W, Chan JKC, Dorfman DM (2004) Spindle cell tumour with thymus-like differentiation. In: DeLellis RA,Lloyd RV, Heitz PU, et al, eds. Pathology and genetics of tumours of endocrine organs. Lyon, France:IARC Press; 96-97. World Health Organization classification of tumours.

4. Roka S, Kornek G, Schüller J, Ortmann E, Feichtinger J, Armbruster C (2004) Carcinoma showing thymiclike elements- a rare malignancy of the thyroid gland. Br J Surg 91: 142-145.

5. Ito Y, Miyauchi A, Nakamura Y, Miya A, Kobayashi K, Kakudo K (2007) Clinicopathologic significance of intrathyroidal epithelial thymoma/carcinoma showing thymus-like differentiation: a collaborative study with Member Institutes of The Japanese Society of Thyroid Surgery. Am J Clin Pathol 127: 230-236.

6. Yoneda K, Matsui O, Kobayashi T, Gabata T, Minato H, Hirokawa M (2005) CT and MRI findings of carcinoma showing thymus-like differentiation. Radiat Med 23: 451-455.

7. Da J, Shi H, Lu KJ (1999) Thyroid squamous-cell carcinoma showing thymus-like element (CASTLE): a report of eight cases. Zhonghua Zhong Liu Za Zhi 21: 303-304.

8. Kakudo K, Mori I, Tamaoki N, Watanabe K (1988) Carcinoma of possibile thymic origin presenting as a thyroid mass: a new subgroup of squamous cell carcinoma of the thyroid. J Surg Oncol 38: 187-192.

9. Luo CM, Hsueh C, Chen TM (2005) Extrathyroid carcinoma showing thymus-like differentiation (CASTLE) tumor: a new case report and review of literature. Head Neck 27: 927-933.

10. Piacentini MG, Romano F, De Fina S, Sartori P, Leone EB, Rubino B, Uggeri F (2006) Carcinoma of the neck showing thymic-like elements (CASTLE): report of a case and review of the literature. In J Surg Pathol 14: 171-175.

11. Ito Y, Miyauchi A, Arai K, Nozawa R, Miya A, Kobayashi K, Nakamura Y, Kakudo K (2006) Usefulness of S100A9 for diagnosis of intrathyroid epithelial thymoma (ITET)/carcinoma showing thymus-like differentiation (CASTLE). Pathology 38: 541-544.

12. Matsuura B, Tokunaga H, Miyake T, Utsunomiya S, Minami H, Onji M (2004) A case of malignant thymoma mimicking thyroid carcinoma: a pitfall in fineneedle aspiration. Endocrine Journal 51: 237-241.

13. Caturelli E, Rapaccini GL, Anti M, Fabiano A, Fedeli G (1985) Malignant seeding after fine-needle aspiration biopsy of the pancreas. Diagn Imaging Clin Med 54: 88-91.

14. Berezowski K, Grimes MM, Gal A, Kornstein MJ (1996) CD5 immunoreactivity of epithelial cells in thymic carcinoma and CASTLE using paraffin-embedded tissue. Am J Clin Pathol 106: 483-486.

15. Reimann JR, Dorfman DM, Nosè V (2006) Carcinoma showing thymus-like differentiation of the thyroid (CASTLE): a comparative study: evidence of thymic differentiation and solid cell nest origin. Am J Surg Pathol 30: 994-1001.

16. Pan CC, Chen PC, Chou TY, Chiang H (2003) Expression of calretinin and other mesothelioma-related markers in thymic carcinoma and thymoma. Hum Pathol 34: 1155-1162.

17. Lin K, Nguyen BD, Ettinger DS, Chin BB (1999) Somatostatin receptor scintigraphy and somatostatin theraphy in the evaluation and treatment of malignant 
thymoma. Clin Nucl Med 24: 24-28.

18. Ordonez GN (2005) Immunohistochemical diagnosis of epithelioid mesothelioma. Arch Pathol Lab Med 129: $1407-1414$.

19. Tomiyama $\mathrm{N}$, Honda $\mathrm{O}$, Tsubamoto $\mathrm{M}$, Inoue $\mathrm{A}$, Sumikawa H, Kuriyama K, Kusumoto M, Johkoh T, Nakamura H (2007) Anterior mediastinal tumors: diagnostic accuracy of CT and MRI. Eur J Radiol (In press).

20. Hirooka $\mathrm{Y}$, Goto $\mathrm{H}$, Itoh $\mathrm{A}$, Hashimoto $\mathrm{S}$, Niwa $\mathrm{K}$, Ishikawa H, Okada N, Itoh T, Kawashima H (2003) Case of intraductal papillary mucinous tumor in which endosonography-guided fine-needle aspiration biopsy caused dissemination. $J$ Gastroenterol Hepatol 18: 1323-1324.

21. Postovsky S, Elhasid R, Ben Arush MW, Berant M, Hayari L, Ofer A (2001) Local dissemination of hepatocellular carcinoma in a child after fine-needle aspiration. Med Pediatr oncol 36: 667-668.

22. Voravud N, Shin DM, Dekmezian RH, Dimery I, Lee JS, Hong WK (1992). Implantation metastasis of carcinoma after percutaneous fine-needle aspiration biopsy.
Chest 102: 313-315.

23. Boutin C, Rey F, Viallat JR (1995) Prevention of malignant seeding after invasive diagnostic procedures in patients with pleural mesothelioma: a randomized trial of local radiotherapy. Chest 108: 754-758.

24. West D, Foord T, Davies R (2006) Needle-trach metastasis and prophylactic radiotherapy for mesothelioma. Respir Med 100: 1037-1040.

25. Mizukami Y, Kurumaya H, Yamada T, Minato H, Nonomura A, Noguchi M, Matsubara F (1995) Thymic carcinoma involving the thyroid gland: report of two cases. Hum Pathol 26: 576-579.

26. Kusada N, Hara Y, Kobayashi S, Weihua T, Nakamura Y, Kakudo K, Yuasa H (2005) A case of aggressive carcinoma showing thymus-like differentiation with distant metastases. Thyroid 12: 1383-1388.

27. Ferone D, van Hagen MP, Kwekkeboom DJ, van Koetsveld PM, Mooy DM, Lichtenauer-Kaligis E, Schönbrunn A, Colao A, Lamberts SW, Hofland LJ (2000) Somatostatin receptor subtypes in human thymoma and inhibition of cell proliferation by octreotide in vitro. J Clin Endocrinol Metab 85: 1719-1726. 